\title{
LETTER
}

\section{Selective decontamination: no oracle needed}

\author{
Elan Gorshein ${ }^{1 *}$, Prapti Shingala ${ }^{1}$, Lindsay Elbaum ${ }^{2}$, Naynesh Patel ${ }^{3}$ and Amay Parikh ${ }^{4}$ \\ See related research by Cuthbertson et al., http://ccforum.com/content/17/6/R266
}

We read with interest the study by Cuthbertson and colleagues [1] in a recent issue of Critical Care, and we appreciate their attempts to support studies regarding selective decontamination of the digestive tract (SDD). However, we have some concerns.

The argument supporting a randomized controlled trial (RCT) for the evaluation of SDD is ambiguous. The Delphi method embraces 'quasi-anonymity', in which the researcher is aware of the responses of the participants [2]. The selection of experts is prone to bias, as participants were chosen on the basis of their inclusion among a particular group. Moreover, participants' perception of SDD via a self-rated questionnaire is often misleading. Capacity to accurately reflect upon self-knowledge may be skewed, as we inflate the scope of our experience and understanding. The validity of a consensus is dubious, as dissidents are encouraged to alter their responses so as to better comport with the majority [2]. Knowing the time frame between rounds would be useful for readers.

Using the Delphi technique and examining barriers to implementation may be novel, but the need for further evidence of effectiveness of SDD is not the limiting factor to widespread application. Given the 36 RCTs referenced, which consistently support its use, the benefits of SDD are proven, but rather the hindrance appears to be the lack of public attention or the concern for antibiotic resistance [3]. The digestive tract is particularly fragile in critically ill patients, and antibiotics have been shown to destabilize the gut microbiome, and this may increase developing resistance [4].

Notwithstanding these remarks, the authors highlight a promising intervention. Antibiotic resistance is an ongoing concern and should serve to prompt future studies.

\section{Authors' response \\ Brian H Cuthbertson and Jill Francis}

We disagree that the argument supporting an RCT is ambiguous. We have clearly demonstrated that the vast majority of respondents agreed this was necessary. They also agreed that such a trial was ethical and that they would take part.

The argument that the method embraces 'quasi-anonymity' is also unjustified as the key to anonymity in a Delphi is that the survey participants are blinded to the identities of other participants at all times and this was achieved.

We do not agree that including only key stakeholder groups introduces a bias as a bias introduces a systematic error, whereas we believe the effect of our enrollment strategy could only reduce the generalizability of the result. The authors are incorrect when they state that the 'validity of the consensus is dubious' since we

\footnotetext{
* Correspondence: elan.gorshein@gmail.com

${ }^{1}$ Internal Medicine Division, Department of Medicine, Rutgers Robert Wood Johnson Medical School, 1 Robert Wood Johnson Place, P.O. Box 19, New Brunswick, NJ 08903-0019, USA

Full list of author information is available at the end of the article
}

did not attempt to achieve consensus and no consensus was identified.

We do agree that participants' perception of any issue via a self-rated questionnaire is often misleading if the objective of the study is to identify clinical 'truth'. However, perceptions drive behavior and give insights into the thinking that may influence practice.

Our colleagues state that 'the need for further evidence of effectiveness of SDD is not the limiting factor to widespread application'. It is unclear where the authors derived this statement, but it appears to be opinionbased and is therefore prone to bias. Conversely, we have produced specific evidence that there was a perceived need for more generalizable evidence with regard to effectiveness and ecological impact.

\footnotetext{
Abbreviations

RCT: Randomized controlled trial; SDD: Selective decontamination of the digestive tract.
} 


\section{Competing interests}

The authors declare that they have no competing interests.

\section{Author details}

${ }^{1}$ Internal Medicine Division, Department of Medicine, Rutgers Robert Wood Johnson Medical School, 1 Robert Wood Johnson Place, P.O. Box 19, New Brunswick, NJ 08903-0019, USA. ${ }^{2}$ Rutgers Robert Wood Johnson Medical School, 1 Robert Wood Johnson Place, New Brunswick, NJ 08903-0019, USA. ${ }^{3}$ Pulmonary and Critical Care Division, Department of Medicine, Rutgers Robert Wood Johnson Medical School, 1 Robert Wood Johnson Place, P.O. Box 19, New Brunswick, NJ 08903-0019, USA. ${ }^{4}$ Divisions of Nephrology and Pulmonary/Critical Care, Department of Medicine, Rutgers Robert Wood Johnson Medical School, 1 Robert Wood Johnson Place, P.O. Box 19, New Brunswick, NJ 08903-0019, USA.

\section{Published: 12 March 2014}

\section{References}

1. Cuthbertson BH, Campbell MK, Maclennan G, Duncan EM, Marshall AP, Wells EC, Prior ME, Todd L, Rose L, Seppelt IM, Bellingan G, Francis JJ: Clinical stakeholders' opinions on the use of selective decontamination of the digestive tract in critically ill patients in intensive care units: an international Delphi study. Crit Care 2013, 17:R266.

2. Keeney S, Hasson F, McKenna H: Consulting the oracle: ten lessons from using the Delphi technique in nursing research. J Adv Nurs 2006, 53:205-212.

3. Daneman N, Sarwar S, Fowler RA, Cuthbertson BH, SuDDICU Canadian Study Group: Effect of selective decontamination on antimicrobial resistance in intensive care units: a systematic review and meta-analysis. Lancet Infect Dis 2013, 13:328-341.

4. Carlet J: The gut is the epicentre of antibiotic resistance. Antimicrob Resist Infect Control 2012, 1:39.

doi:10.1186/cc13765

Cite this article as: Gorshein et al:: Selective decontamination: no oracle needed. Critical Care 2014 18:417. 